\title{
Cancer excess after arsenic exposure from contaminated milk powder
}

\author{
Takashi Yorifuji • Toshihide Tsuda • \\ Hiroyuki Doi · Philippe Grandjean
}

Received: 23 July 2010/Accepted: 3 September 2010/Published online: 29 September 2010

(c) The Japanese Society for Hygiene 2010

\begin{abstract}
Objectives Long-term exposure to inorganic arsenic is related to increased risk of cancer in the lung, skin, bladder, and, possibly, other sites. However, little is known about the consequences of developmental exposures in regard to cancer risk. During early summer in 1955, mass arsenic poisoning of infants occurred in the western part of Japan because of contaminated milk powder. Okayama Prefecture was most severely affected. We examined whether the affected birth cohorts in this prefecture experienced increased cancer mortality.

Methods We targeted subjects who were born from September 1950 to August 1960 and died in Okayama Prefecture between January 1969 and March 2008 due to malignant neoplasm $(N=3,141)$. We then compared cancer mortality (total, liver, pancreatic, lung, bladder/ kidney, and hematopoietic cancers) between cohorts born before the milk poisoning (exposed group) and cohorts
\end{abstract}

T. Yorifuji $(\bowtie) \cdot$ P. Grandjean

Department of Environmental Health, Harvard School of Public

Health, 401 Park Drive, 3-112-12 East, Boston, MA 02215, USA

e-mail: tyorifuj@hsph.harvard.edu;

yorichan@md.okayama-u.ac.jp

T. Yorifuji · H. Doi

Department of Epidemiology, Okayama University Graduate

School of Medicine, Dentistry and Pharmaceutical Sciences,

Okayama, Japan

T. Tsuda

Department of Environmental Epidemiology,

Okayama University Graduate School of Environmental

Science, Okayama, Japan

P. Grandjean

Department of Environmental Medicine,

University of Southern Denmark, Odense C, Denmark born after the poisoning (nonexposed group). We estimated mortality ratios and $95 \%$ confidence intervals.

Results Total and liver cancers were elevated in the cohort up to 1 year of age at time of the poisoning. In addition, pancreatic and hematopoietic cancers were elevated in the cohorts up to 5 years of age, and mortality ratios were approximately twice those of the nonexposed group. Increased risk of lung and bladder/kidney cancers was not apparent.

Conclusions Although dilution is present in these cohortbased data, our study highlights the notion that developmental arsenic exposure may lead to a different pattern of cancer, including increases in pancreatic and hematopoietic cancer, as compared with adult or lifetime exposures to inorganic arsenic.

Keywords Milk substitute $\cdot$ Food contamination · Arsenic $\cdot$ Pancreatic neoplasms $\cdot$ Leukemia

\section{Introduction}

Long-term exposure to inorganic arsenic through inhalation or drinking-water ingestion is causally related to increased risk of cancer in the lung, skin, and bladder [1-3]. Although the evidence is less convincing, an association between inorganic arsenic and increased risk of kidney, liver, and prostate cancer is also possible [1]. This conclusion mainly relies on chronic exposures. Although health effects of early-life exposure to arsenic have been receiving attention $[4,5]$, little is known about the consequences of exposures during infancy.

During early summer in 1955 , mass arsenic poisoning of bottle-fed infants occurred in the western part of Japan because of contaminated milk powder [6]. Although the 
contaminated milk was announced as the cause of the poisoning and ordered to be recalled on August 24th, contamination continued for at least 4 months [7]. Affected infants manifested skin pigmentation, diarrhea, and fever, and more than one hundred died from acute poisoning [7]. The estimated total dose of arsenic leading to diagnosis was $60 \mathrm{mg}$ [6]. Although subsequent studies demonstrated high incidence of neurological disorders [8] and skin disorders [9] among affected subjects as they reached adolescence or adulthood, a follow-up study of officially recognized patients up to 40 years old did not provide definitive evidence of increased cancer mortality [10]. However, this follow-up study had limited statistical power.

The contaminated milk powder was shipped all over Japan, but consumption of at least 33,500 one-pound cans of contaminated milk powder makes Okayama Prefecture the most severely affected area in the country [7]. Although Okayama represents less than $2 \%$ of the Japanese population, the 2,005 infants who were poisoned or died in Okayama represent $17 \%$ of the total number of affected children [7]. We thus targeted Okayama Prefecture in our previous preliminary study and compared cancer mortality between a 5-year birth cohort including subjects born before milk poisoning (exposed group) and a 5-year cohort born after milk poisoning (control group) [11]. Then, we showed that mortality from skin cancer, liver cancer, pancreatic cancer, and leukemia were elevated in the exposed group [11]. However, since we at first could only obtain numbers of mortality cases summed up in 5-year age intervals from published vital statistics reports, with numbers starting from January each year, we could not separate the cohorts in regard to the time of the poisoning event, thus introducing exposure misclassification.

In the present study, we therefore obtained individual mortality information in Okayama in relation to exact birth date and examined in greater detail whether the poisoning event was associated with cancer mortality excess.

\section{Materials and methods}

\section{Study design and population}

In the absence of a national cancer registry, we obtained anonymized mortality information files without the name and addresses of the deceased from the Ministry of Health, Labor, and Welfare in Japan, in compliance with Japanese law. We retrieved information on subjects born from September 1950 to August 1960 and who died in Okayama Prefecture, Japan, between January 1969 and March 2008 due to malignant neoplasm, as this time period was accessible from the data files $(N=3,141)$.

\section{Outcomes}

We examined both total cancer and cancer at individual sites, with particular emphasis on sites previously shown to be associated with arsenic or associated with the milk poisoning episode in our previous study: liver, pancreas, lung, bladder/kidney, and hematopoietic system. The latter includes lymphoma, myeloma, and leukemia. Individual sites were grouped using the International Classification of Disease (ICD) 8-10, depending on year of death. Although the coding (ICD) changed three times during the study period, changes affected mortality statistics for all of Japan, and we could therefore classify the same category of cancer throughout the period.

\section{Analyses}

We compared cancer mortality in exposed and nonexposed subjects in three different ways. In the first comparison (up to 1 year of age), we compared cancer mortality between two cohorts at the same ages: a 1-year cohort including subjects born between August 1954 to July 1955 (exposed group) and another 1-year cohort including subjects born from September 1955 to August 1956 (nonexposed group). Thus, for example, we compared the mortality rates of subjects who were 21 years old in 1975 and 21 years old in 1976. We excluded subjects born in August 1955 because the milk was recalled in the middle of August, and subjects born that month may or may not have been exposed to arsenic at a level similar to those born during the previous months.

We conducted a second comparison similar to our previous report for subjects up to 5 years of age. Because we had used the vital statistics report in the previous study, with the total number of mortality cases summed up in 5 -year age intervals, we could not separate cohorts before and after the poisoning. Now, we compared cancer mortality between two cohorts at the same ages, i.e., a 5-year cohort including subjects born from September 1950 to July 1955 (exposed group) and another 5-year cohort of subjects born from September 1955 to August 1960 (nonexposed group). For example, we compared the mortality rate of people who were 21 years old in 1971-1975 with subjects who were 21 years old in 1976-1980. The latter group was used as the nonexposed group. We could not include subjects born in August 1950 due to lack of data.

In the third comparison (above 1 year and up to 5 years of age), we used the same nonexposed group in the comparison of up to 5-year-old (mentioned above), but targeted people who were aged 1 to 4 years old (under 5 years) at the poisoning as the exposed group. Thus, we compared cancer mortality between a cohort that included subjects born from September 1950 to July 1954 (exposed group) 
and another cohort of subjects born from September 1955 to August 1960 (nonexposed group). Again, we therefore compared the mortality rate of subjects aged 21 years in 1971-1974 with subjects who were 21 years old in 1976-1980. In a sensitivity analysis, we also used a cohort of subjects born from September 1956 to August 1960 as the nonexposed group.

In all of the comparisons, since the numbers of cancer deaths were small and the national census is carried out at 5-year intervals all over Japan (1970, 1975, 1980, etc.), we summed the number of cancer deaths during each 5-year period, centering on the census year. Furthermore, we assumed that the number of people was the same during the period 2 years before and after the census year (1969-1972, 1973-1977, 1978-1982, etc.). In the comparisons, we first calculated the expected number of mortality cases in the exposed group during 5 years by multiplying the number of population in the exposed groups by rates of mortality in the nonexposed groups. Then, we calculated mortality ratios (MRs) during 5 years by dividing the observed number of mortality cases in the exposed groups by the expected number of mortality cases obtained above. We also estimated MRs during the whole study period. Finally, we estimated 95\% Wald confidence intervals (CIs) under the assumption of Poisson distribution [12].

\section{Results}

Comparison of 1-year cohorts

The numbers of deaths in the exposed group in the up to 1-year comparison, and MRs and their CIs for all cancers, are shown in Table 1. While the mortality from total cancers (ages 48-53 years) and liver cancer (all ages) were significantly or almost significantly elevated in the exposed cohort $(\mathrm{MR}=1.36,95 \%$ CI $1.03-1.78$ and $\mathrm{MR}=1.72$, 95\% CI 0.99-2.97), mortality from other cancers was not elevated.

Comparison of 5-year cohorts

Comparable with the up to 1 year comparison, mortality from total cancers (ages 28-37, 43-53 years, and all ages)

Table 1 Number of cancer deaths in the exposed group and mortality ratios in the comparison of 1-year-old cohorts

\begin{tabular}{|c|c|c|c|c|c|c|}
\hline Period & Total & Liver & Pancreas & Lung & Bladder/kidney & Hematopoietic $^{\mathrm{a}}$ \\
\hline $\begin{array}{l}\text { Number of deaths in exposed group in } \\
1983-1987\end{array}$ & 15 & 0 & 0 & 0 & 0 & 2 \\
\hline MR with $95 \%$ confidence interval & $\begin{array}{l}1.16 \\
\quad(0.55-2.43)\end{array}$ & $\mathrm{NE}$ & NE & $\mathrm{NE}$ & $\mathrm{NE}$ & $\begin{array}{l}0.67 \\
\quad(0.11-4.00)\end{array}$ \\
\hline $\begin{array}{l}\text { Number of deaths in exposed group in } \\
1988-1992\end{array}$ & 22 & 3 & 0 & 0 & 2 & 1 \\
\hline MR with $95 \%$ confidence interval & $\begin{array}{l}1.11 \\
\quad(0.60-2.03)\end{array}$ & NE & $\mathrm{NE}$ & NE & $\mathrm{NE}$ & $\begin{array}{l}1.01 \\
(0.06-16.11)\end{array}$ \\
\hline $\begin{array}{l}\text { Number of deaths in exposed group in } \\
1993-1997\end{array}$ & 37 & 6 & 0 & 2 & 0 & 4 \\
\hline MR with $95 \%$ confidence interval & $\begin{array}{l}1.06 \\
(0.67-1.68)\end{array}$ & $\begin{array}{l}1.20 \\
(0.37-3.94)\end{array}$ & $\mathrm{NE}$ & $\begin{array}{l}0.50 \\
\quad(0.09-2.74)\end{array}$ & $\mathrm{NE}$ & $\begin{array}{l}1.34 \\
(0.30-5.97)\end{array}$ \\
\hline $\begin{array}{l}\text { Number of deaths in exposed group in } \\
1998-2002\end{array}$ & 70 & 9 & 5 & 4 & 1 & 2 \\
\hline MR with $95 \%$ confidence interval & $\begin{array}{l}0.95 \\
\quad(0.68-1.32)\end{array}$ & $\begin{array}{l}1.81 \\
\quad(0.61-5.39)\end{array}$ & $\begin{array}{l}1.25 \\
(0.34-4.67)\end{array}$ & $\begin{array}{l}0.31 \\
\quad(0.10-0.95)\end{array}$ & $\begin{array}{l}1.00 \\
(0.06-16.04)\end{array}$ & $\begin{array}{l}0.33 \\
\quad(0.07-1.66)\end{array}$ \\
\hline $\begin{array}{l}\text { Number of deaths in exposed group in } \\
2003-2007\end{array}$ & 133 & 17 & 9 & 13 & 2 & 7 \\
\hline MR with $95 \%$ confidence interval & $\begin{array}{l}1.36 \\
(1.03-1.78)\end{array}$ & $\begin{array}{l}1.62 \\
(0.72-3.63)\end{array}$ & $\begin{array}{l}1.93 \\
(0.59-6.26)\end{array}$ & $\begin{array}{l}1.11 \\
\quad(0.49-2.54)\end{array}$ & $\mathrm{NE}$ & $\begin{array}{l}0.86 \\
\quad(0.30-2.44)\end{array}$ \\
\hline $\begin{array}{l}\text { Number of deaths in exposed group in } \\
1969-2007^{\mathrm{b}}\end{array}$ & 296 & 35 & 14 & 19 & 4 & 23 \\
\hline Total MR with $95 \%$ confidence interval & $\begin{array}{l}1.11 \\
\quad(0.94-1.31)\end{array}$ & $\begin{array}{l}1.72 \\
\quad(0.99-2.97)\end{array}$ & $\begin{array}{l}1.06 \\
(0.50-2.25)\end{array}$ & $\begin{array}{l}0.62 \\
\quad(0.35-1.10)\end{array}$ & $\begin{array}{l}3.92 \\
\quad(0.44-35.12)\end{array}$ & $\begin{array}{l}0.64 \\
\quad(0.38-1.09)\end{array}$ \\
\hline
\end{tabular}

Exposed group: born from August 1954 to July 1955; unexposed group: born from September 1955 to August 1956

$M R$ mortality ratio, $N E$ not estimated due to small numbers

${ }^{a}$ Hematopoietic cancer includes lymphoma, myeloma, and leukemia

b Total mortality is for 1969-2007, but individual 5-year comparisons are only shown for 1983-2007 because of small numbers of deaths 
Table 2 Number of cancer deaths in the exposed group and mortality ratios in the comparison of 5-year cohorts

\begin{tabular}{|c|c|c|c|c|c|c|}
\hline Period & Total & Liver & Pancreas & Lung & Bladder/kidney & Hematopoietic $^{\mathrm{a}}$ \\
\hline $\begin{array}{l}\text { Number of deaths in exposed group in } \\
1983-1987\end{array}$ & 147 & 10 & 6 & 0 & 3 & 27 \\
\hline MR with $95 \%$ confidence interval & $\begin{array}{l}1.41 \\
(1.08-1.82)\end{array}$ & $\begin{array}{l}2.22 \\
(0.70-7.09)\end{array}$ & $\begin{array}{l}1.33 \\
(0.38-4.73)\end{array}$ & NE & NE & $\begin{array}{l}2.40 \\
\quad(1.16-4.96)\end{array}$ \\
\hline $\begin{array}{l}\text { Number of deaths in exposed group in } \\
1988-1992\end{array}$ & 216 & 12 & 7 & 1 & 1 & 27 \\
\hline MR with $95 \%$ confidence interval & $\begin{array}{l}1.19 \\
(0.97-1.45)\end{array}$ & $\begin{array}{l}0.67 \\
\quad(0.32-1.42)\end{array}$ & $\begin{array}{l}1.25 \\
(0.40-3.95)\end{array}$ & $\begin{array}{l}0.04 \\
\quad(0.01-0.29)\end{array}$ & $\begin{array}{l}0.45 \\
\quad(0.04-4.94)\end{array}$ & $\begin{array}{l}1.73 \\
(0.91-3.29)\end{array}$ \\
\hline $\begin{array}{l}\text { Number of deaths in exposed group in } \\
1993-1997\end{array}$ & 365 & 29 & 18 & 35 & 4 & 28 \\
\hline MR with $95 \%$ confidence interval & $\begin{array}{l}1.11 \\
(0.95-1.29)\end{array}$ & $\begin{array}{l}1.72 \\
(0.92-3.21)\end{array}$ & $\begin{array}{l}0.94 \\
\quad(0.49-1.83)\end{array}$ & $\begin{array}{l}0.74 \\
\quad(0.47-1.16)\end{array}$ & $\begin{array}{l}3.56 \\
(0.40-31.83)\end{array}$ & $\begin{array}{l}0.96 \\
\quad(0.56-1.63)\end{array}$ \\
\hline $\begin{array}{l}\text { Number of deaths in exposed group in } \\
1998-2003\end{array}$ & 734 & 100 & 54 & 88 & 7 & 40 \\
\hline MR with $95 \%$ confidence interval & $\begin{array}{l}1.27 \\
(1.11-1.45)\end{array}$ & $\begin{array}{l}1.47 \\
(0.99-2.17)\end{array}$ & $\begin{array}{l}1.93 \\
(1.07-3.47)\end{array}$ & $\begin{array}{l}1.13 \\
(0.77-1.64)\end{array}$ & $\begin{array}{l}1.16 \\
(0.30-4.50)\end{array}$ & $\begin{array}{l}1.00 \\
(0.58-1.71)\end{array}$ \\
\hline $\begin{array}{l}\text { Number of deaths in exposed group in } \\
1969-2003^{\mathrm{b}}\end{array}$ & 1630 & 153 & 87 & 127 & 16 & 171 \\
\hline Total MR with $95 \%$ confidence interval & $\begin{array}{l}1.37 \\
(1.27-1.48)\end{array}$ & $\begin{array}{l}1.73 \\
\quad(1.31-2.28)\end{array}$ & $\begin{array}{l}1.79 \\
\quad(1.23-2.61)\end{array}$ & $\begin{array}{l}0.98 \\
\quad(0.76-1.27)\end{array}$ & $\begin{array}{l}2.20 \\
(0.86-5.62)\end{array}$ & $\begin{array}{l}1.26 \\
\quad(0.99-1.60)\end{array}$ \\
\hline
\end{tabular}

Exposed group: born from September 1950 to July 1955; unexposed group: born from September 1955 to August 1960

$M R$ mortality ratio, $N E$ not estimated due to small numbers

${ }^{\text {a }}$ Hematopoietic cancer includes lymphoma, myeloma, and leukemia

b Total mortality is for 1969-2003, but individual 5-year comparisons are only shown for 1983-2003 because of small numbers of deaths

and liver cancer (all ages) were significantly elevated to the same extent (Table 2). In addition, MRs of pancreatic cancer (ages 43-53 and all ages) and hematopoietic cancer (ages 28-37 years) were significantly elevated, and both MRs were about twice the magnitude of those of nonexposed group. Mortality from neither lung cancer nor bladder/renal was elevated in the exposed cohort.

Comparison of cohorts of above 1 and up to 5 years old

We observed the same tendency and similar magnitude of MRs even in the comparison of above 1 and up to 5 years old cohorts (Table 3). Even if we used the alternative nonexposed group (people born during the period from September 1956 to August 1960), the results did not change.

\section{Discussion}

In the present study, we adopted an improved ecological study design and examined whether the poisoning was associated with cancer mortality excess in Okayama Prefecture, Japan. Total and liver cancers were elevated in the comparison of cohorts up to 1 year old at the poisoning. In addition, pancreatic and hematopoietic cancers were elevated in the comparison of cohorts up to 5 years old. In contrast, we did not find increased risk of lung and bladder/ kidney cancers.

The elevated mortality from liver cancer is comparable to previous studies $[13,14]$. While little attention has been paid to pancreatic and hematopoietic cancer as possible targets of arsenic exposure, the elevated mortality ratios in the younger age groups are consistent with our preliminary study [11]. In considering the plausibility of these observations, arsenic is reported to induce type 2 diabetes mellitus [15], and diabetes mellitus is thought to be a risk factor for pancreatic cancer [16]. Thus, the association with pancreatic cancer might be biologically meaningful. The association with hematopoietic cancer is consistent with a previous environmental study [17, 18], and the observed narrow latency interval is similar to observations in regard to leukemogenic chemicals [19].

In contrast, we did not find an increased risk of lung and bladder/kidney cancers otherwise shown to be associated with chronic arsenic exposure [2, 3] or early-life arsenic exposure [20]. The lack of association might be derived from dilution in a population less than 53 years of age, or the effects of intensive follow-up of affected patients, where early detection may concentrate on lung and bladder/kidney cancers, which might lead to better prognosis (since these cancers are suspected effects of arsenic). Also, the 
Table 3 Number of cancer deaths in the exposed group and mortality ratios in the comparison of cohorts of 1 to up to 5 years old

\begin{tabular}{|c|c|c|c|c|c|c|}
\hline Period & Total & Liver & Pancreas & Lung & Bladder/kidney & Hematopoietic $^{\mathrm{a}}$ \\
\hline $\begin{array}{l}\text { Number of deaths in exposed group in } \\
1983-1987\end{array}$ & 124 & 8 & 6 & 0 & 1 & 25 \\
\hline MR with $95 \%$ confidence interval & $\begin{array}{l}1.45 \\
\quad(1.11-1.90)\end{array}$ & $\begin{array}{l}2.18 \\
\quad(0.66-7.24)\end{array}$ & $\begin{array}{l}1.64 \\
\quad(0.46-5.79)\end{array}$ & NE & NE & $\begin{array}{l}2.73 \\
\quad(1.31-5.67)\end{array}$ \\
\hline $\begin{array}{l}\text { Number of deaths in exposed group in } \\
1988-1992\end{array}$ & 183 & 7 & 7 & 0 & 1 & 24 \\
\hline MR with $95 \%$ confidence interval & $\begin{array}{l}1.24 \\
(1.00-1.53)\end{array}$ & $\begin{array}{l}0.48 \\
\quad(0.20-1.17)\end{array}$ & $\begin{array}{l}1.54 \\
(0.49-4.86)\end{array}$ & NE & $\begin{array}{l}0.55 \\
\quad(0.05-6.07)\end{array}$ & $\begin{array}{l}1.89 \\
(0.98-3.65)\end{array}$ \\
\hline $\begin{array}{l}\text { Number of deaths in exposed group in } \\
1993-1997\end{array}$ & 301 & 22 & 14 & 31 & 3 & 25 \\
\hline MR with $95 \%$ confidence interval & $\begin{array}{l}1.12 \\
(0.95-1.32)\end{array}$ & $\begin{array}{l}1.60 \\
(0.83-3.08)\end{array}$ & $\begin{array}{l}0.90 \\
\quad(0.44-1.82)\end{array}$ & $\begin{array}{l}0.80 \\
\quad(0.51-1.28)\end{array}$ & $\begin{array}{l}3.27 \\
(0.34-31.45)\end{array}$ & $\begin{array}{l}1.05 \\
(0.61-1.82)\end{array}$ \\
\hline $\begin{array}{l}\text { Number of deaths in exposed group in } \\
1998-2003\end{array}$ & 590 & 80 & 43 & 74 & 6 & 40 \\
\hline MR with $95 \%$ confidence interval & $\begin{array}{l}1.25 \\
(1.09-1.44)\end{array}$ & $\begin{array}{l}1.44 \\
(0.97-2.15)\end{array}$ & $\begin{array}{l}1.88 \\
(1.03-3.44)\end{array}$ & $\begin{array}{l}1.16 \\
(0.79-1.71)\end{array}$ & $\begin{array}{l}1.23 \\
(0.31-4.90)\end{array}$ & $\begin{array}{l}1.23 \\
(0.72-2.10)\end{array}$ \\
\hline $\begin{array}{l}\text { Number of deaths in exposed group in } \\
1969-2003^{\mathrm{b}}\end{array}$ & 1344 & 119 & 72 & 108 & 12 & 158 \\
\hline Total MR with $95 \%$ confidence interval & $\begin{array}{l}1.39 \\
(1.28-1.50)\end{array}$ & $\begin{array}{l}1.65 \\
\quad(1.23-2.20)\end{array}$ & $\begin{array}{l}1.82 \\
\quad(1.24-2.68)\end{array}$ & $\begin{array}{l}1.02 \\
\quad(0.78-1.33)\end{array}$ & $\begin{array}{l}2.02 \\
\quad(0.76-5.38)\end{array}$ & $\begin{array}{l}1.43 \\
\quad(1.12-1.82)\end{array}$ \\
\hline
\end{tabular}

Exposed group: born from September 1950 to July 1954; unexposed group: born from September 1955 to August 1960

$M R$ mortality ratio, $N E$ not estimated due to small numbers

${ }^{\text {a }}$ Hematopoietic cancer includes lymphoma, myeloma, and leukemia

b Total mortality is for 1969-2003, but individual 5-year comparisons are only shown for 1983-2003 because of small numbers of deaths

follow-up may likely involve efforts to encourage smoking cessation. Moreover, developmental arsenic exposures in infancy might have different effects on cancer.

Up to now, two large follow-up studies of affected patients have been carried out: The first study identified 588 patients who died up to March 1982 among 12,368 patients recognized by the Japanese Ministry of Health and Labor [21]. The authors then selected 155 patients born from 1953 to 1955 and who had died between 1960 and March 1982 (thereby excluding 93 patients born before or after the period and 340 patients who died between 1955 and 1959). Although the standardized mortality ratio (SMR) of total cancers was not elevated $(n=9$, SMR $=$ 1.05), the SMR for cancer of the brain and central nervous system was significantly elevated $(n=4, \mathrm{SMR}=11.11$, $P<0.01)$. The second study expanded the follow-up period and targeted patients who were born from 1953 to 1955 and died between 1982 and 2004 among 5,064 patients followed by the Hikari Association [10]. The Hikari Association is a public-interest foundation for permanent relief of the victims of the contaminated milk powder [22]. In this study, the authors found no increased mortality of total cancers $(n=34$, SMR $=1.0,95 \%$ confidence interval $0.69-1.37$ ), and the same was true for cancers at individual sites. Although these two individual follow-up studies are of great value, they are limited by follow-up through less than 50 years of age and by small numbers of cases, which may make it difficult for these studies to identify any increased cancer mortality. Furthermore, a possible reason that they did not find an increased risk could be related to the fact that they restricted eligible subjects to those aged less than 2 years at time of exposure. When we compared 2-year cohorts using the vital statistics utilized in the present study, we observed increased pancreatic cancer mortality $(n=18, \mathrm{MR}=4.06,95 \% \mathrm{CI}$ 1.20-13.79), but we did not observe increased risk at other cancer sites.

Indeed, increased risk of cancers was more apparent in the comparison of cohorts of above 1 and up to 5 years old at the poisoning than the comparison of cohorts up to 1 year old. Although about $69 \%$ of official patients were under 1 year old when the poisoning happened, $31 \%$ of the patients ranged from 1 to 4 years old [7]. Moreover, many children aged above 1 year would receive powdered milk as a substitute for fresh milk at that time. Thus, the findings of increased risk for children aged 1-4 years old at the poisoning are not unexpected. The clearer findings within the older age group could be due to the following reasons: first, the number of cases in the up to 1 year old comparison was smaller. Second, all of the deaths due to the contaminated milk in Okayama Prefecture occurred in infants less than 13 months old, thus competing risks might 
have existed in the younger cohort. Finally, biological mechanisms such as differential development of organs or different timing of DNA methylation [23, 24] might contribute to the findings. Future studies should focus on younger children as well as infants.

As an important weakness, this study involves dilution due to its ecological design, where arsenic exposure is defined on the basis of birth date only. However, the number of patients in Okayama Prefecture is reported to be 2,005, and at least 33,500 one-pound cans were consumed in Okayama [7]. Because the dose of poisoned milk powder needed to cause clinical poisoning in an infant corresponds to five cans [6], the number of possible acute poisonings in Okayama could, therefore, have been three times the official estimate. Because the size of a 5-year birth cohort in Okayama is approximately 150,000 , this means that the number of clinically poisoned subjects may represent only $4 \%$ of the cohort. However, the milk brand which produced the contaminated milk dominated the market, and around $40 \%$ of infants were bottle-fed in Okayama Prefecture at that period [25], thus a large number of infants and young children must have been exposed to some extent, which may make it possible to detect an increased risk of total cancers and cancer of some major sites in spite of the dilution.

Moreover, the ecological study design limits the extent to which firm conclusions can be drawn. First, we could not adjust for any calendar effects. However, since the present findings were similar to the preliminary study which did adjust for a calendar effect [11], the effects are thought to be negligible. Second, while we obtained information about subjects who died in Okayama Prefecture, all of them may not have been born in the same prefecture. Thus, exposure misclassification must be present. However, the contaminated milk was distributed all over Japan and this nondifferential misclassification would cause a bias toward the null. Accordingly, this misclassification cannot explain the findings. Third, other cohort effect might also be theoretically possible, but would only be associated with liver, pancreatic, and hematopoietic cancers, thus would be very unlikely.

In conclusion, although dilution is present in these improved ecological data, our study supports our previous findings that pancreatic and hematopoietic cancers are linked to high-level exposures to inorganic arsenic during infancy. In addition to the previous study, this study therefore extends previous findings of increased rates for skin, lung, liver, and urinary tract cancer in populations with long-term arsenic exposures at lower levels. Future studies which target individuals who were affected by arsenic during their infancy are warranted.

Acknowledgments The present study was funded by a grant for young researchers from Okayama University. The authors declare that they have no competing interests. We thank Saori Kashima and Katherine Herz who helped us to conduct the study and prepare the manuscript. We also thank Okayama Prefecture, which helped us to conduct the study.

\section{References}

1. Straif K, Benbrahim-Tallaa L, Baan R, Grosse Y, Secretan B, El Ghissassi F, et al. A review of human carcinogens-part C: metals, arsenic, dusts, and fibres. Lancet Oncol. 2009;10(5):453-4.

2. Tapio S, Grosche B. Arsenic in the aetiology of cancer. Mutat Res. 2006;612(3):215-46.

3. World Health Organization. Environmental health criteria: 224. Arsenic and Arsenic compounds. Geneva: World Health Organization; 2001.

4. Smith AH, Steinmaus CM. Health effects of arsenic and chromium in drinking water: recent human findings. Annu Rev Public Health. 2009;30:107-22.

5. Vahter M. Health effects of early life exposure to arsenic. Basic Clin Pharmacol Toxicol. 2008;102(2):204-11.

6. Dakeishi M, Murata K, Grandjean P. Long-term consequences of arsenic poisoning during infancy due to contaminated milk powder. Environ Health. 2006;5:31.

7. Hamamoto E. Report of arsenic poisoning incident due to powdered milk in Okayama prefecture (in Japanese). Okayama: Department of health, Okayama prefecture; 1957.

8. Ohira M, Aoyama H. Epidemiological studies on the Morinaga powdered milk poisoning (in Japanese with English abstract). Jpn J Hyg. 1973;27(6):500-31.

9. Kawatsu T. Follow-up study of skin symptoms in patients with arsenic poisoning from powdered milk (in Japanese). J Jpn Dermatol Assoc. 1984;94(7):787-95.

10. Tanaka H, Oshima A. Excess mortality among 5, 064 victims of arsenic poisoning from ingestion of arsenic-contaminated "Morinaga dry-milk" in 1955: a prospective study from 1982 to 2004 (in Japanese with English abstract). Nippon Koshu Eisei Zasshi. 2007;54(4):236-45.

11. Yorifuji T, Tsuda T, Grandjean P. Unusual cancer excess after neonatal arsenic exposure from contaminated milk powder. J Natl Cancer Inst. 2010;102(5):360-1.

12. Rothman KJ, Greenland S, Lash TL. Modern epidemiology. 3rd ed. Philadelphia: Wolters Kluwer Health/Lippincott Williams \& Wilkins; 2008.

13. Liaw J, Marshall G, Yuan Y, Ferreccio C, Steinmaus C, Smith $\mathrm{AH}$. Increased childhood liver cancer mortality and arsenic in drinking water in northern Chile. Cancer Epidemiol Biomarkers Prev. 2008;17(8):1982-7.

14. Wu MM, Kuo TL, Hwang YH, Chen CJ. Dose-response relation between arsenic concentration in well water and mortality from cancers and vascular diseases. Am J Epidemiol. 1989;130(6): 1123-32.

15. Diaz-Villasenor A, Burns AL, Hiriart M, Cebrian ME, OstroskyWegman P. Arsenic-induced alteration in the expression of genes related to type 2 diabetes mellitus. Toxicol Appl Pharmacol. 2007;225(2):123-33.

16. Lowenfels AB, Maisonneuve P. Epidemiology and risk factors for pancreatic cancer. Best Pract Res Clin Gastroenterol. 2006;20(2):197-209.

17. Berg JW, Burbank F. Correlations between carcinogenic trace metals in water supplies and cancer mortality. Ann N Y Acad Sci. 1972;199:249-64.

18. Hinwood AL, Jolley DJ, Sim MR. Cancer incidence and high environmental arsenic concentrations in rural populations: results of an ecological study. Int J Environ Health Res. 1999;9:131-41. 
19. Linet MS, Devesa SA, Morgan GJ. The leukemias. In: Schottenfeld D, Fraumeni JF, editors. Cancer epidemiology and prevention. 3rd ed. Oxford, New York: Oxford University Press; 2006.

20. Smith AH, Marshall G, Yuan Y, Ferreccio C, Liaw J, von Ehrenstein $\mathrm{O}$, et al. Increased mortality from lung cancer and bronchiectasis in young adults after exposure to arsenic in utero and in early childhood. Environ Health Perspect. 2006;114(8): 1293-6.

21. Fujimoto I, Hiyama O, Ohshima A, Nakamura M. Studies on the cause of deaths from 1955 to 1982 among arsenic poisoned of the Morinaga milk incident in 1955 (in Japanese). 1988. http:// www.hikari-k.or.jp/ekigaku/frame-h.htm. Accessed 15 July 2010.
22. Hikari Association. What is Hikari Association? (in Japanese). 2010. http://www.hikari-k.or.jp/hikari/frame-a.htm. Accessed 16 July 2010.

23. Chen H, Li S, Liu J, Diwan BA, Barrett JC, Waalkes MP. Chronic inorganic arsenic exposure induces hepatic global and individual gene hypomethylation: implications for arsenic hepatocarcinogenesis. Carcinogenesis. 2004;25(9):1779-86.

24. Reichard JF, Schnekenburger M, Puga A. Long term low-dose arsenic exposure induces loss of DNA methylation. Biochem Biophys Res Commun. 2007;352(1):188-92.

25. Ministry of Heath. Health statistics in Okayama prefecture: Okayama prefecture; 1952. 